\title{
Analysis and Experimentation of the Quad-U Variable Inductor for Power Electronics Applications
}

\author{
J. Marcos Alonso ${ }^{1}$, Marina Perdigão ${ }^{2,3}$, Marco A. Dalla Costa ${ }^{4}$, Shu Zhang ${ }^{5}$, Yijie Wang ${ }^{5}$ \\ (1) University of Oviedo, Electrical Eng. Dept., Campus de Viesques, Gijón, Asturias, Spain. \\ (2) Instituto de Telecomunicações, Coimbra, Portugal. \\ (3) Coimbra Polytechnic - ISEC, Coimbra, Portugal. \\ (4) Federal University of Santa Maria, Group of Intelligence in Lighting (GEDRE), Brazil \\ (5) Harbin Institute of Technology, No. 92, Xidazhi Street, Harbin, 150001, China \\ marcos@uniovi.es; perdigao@isec.pt; marcodc@gedre.ufsm.br; zhangshu0503@126.com; wangyijie@hit.edu.cn
}

\begin{abstract}
In this paper, the analysis of the quad-U variable inductor (VI) is presented. This is an alternative structure of $\mathrm{VI}$ to other ones previously presented and analyzed in the literature, as for example the double-E structure and the triple-E structure. Compared to them, the quad-U structure shows some advantages, namely more symmetrical operation and zero voltage reflected across the bias winding. The superposition law is applied to the equivalent reluctance model in order to solve for DC and AC operation separately. Using the proposed methodology, both AC winding inductance and DC winding inductance can be obtained. An example of analysis is presented for a particular quad-U VI. Simulation and experimental results prove the validity of the proposed analysis and modeling methodology.
\end{abstract}

Keywords: magnetic devices, variable inductor, modeling, reluctance model, inductance, effective inductance.

\section{Introduction}

Variable inductors (VI), also known as controllable inductors, are magnetic elements in which the inductance can be controlled by means of an electrical signal, usually a DC current [1]. These devices have successfully been applied in many power electronics applications, in which they can provide additional control parameters to optimize the converter operation. For instance, they have been used as an additional strategy to control output power in electronic ballast applications [2]-[7]; to provide constant frequency operation in DC-DC resonant converters [8]; to optimize core size in bidirectional DC-DC converters [9]; to improve switching behavior in DC-DC converters [10]; to provide an independent method to control the current through different LED arrays in a one-stage converter [11][12]; to optimize the operation of power factor correction (PFC) converters [13][14]; and to improve regulation and voltage gain in DC-DC converters [15].

Different possibilities have been proposed until now to implement VIs. Among them, most common ones are the double-E structure [17][18], the triple-E structure [14][19] and the quad-U structure [7]. The double-E structure has been thoroughly study in previous publications [17][20]-[22]. The triple-E structure has also been investigated in [14][19]. This structure presents the disadvantage of modulating the permeability of only a small part of the magnetic core. This makes it necessary to handle a high bias current to attain the required excursion of the inductance, which complicates the supplying circuits and increases losses. The quad-U structure has previously been proposed in [7], though it has not yet been studied in detail.

The aim of this paper is to analyze and model the quad-U structure used as VI. The modeling procedure will be similar to that employed in [22], where it is assumed that the $\mathrm{AC}$ component of the magnetic flux is small compared to the DC level. In this way, the superposition law can be used to determine the $\mathrm{AC}$ inductance, which is the variable of interest.
In the following, Section II presents the structure of a quadU VI. Section III presents the analytical modeling based on DC and AC superposed operation. Section IV shows an example of analysis for a particular design. Section VI presents simulation and experimental results. Finally, Section VII presents the conclusions of this work.

\section{Quad-U Variable Inductor}

Fig. 1 illustrates the VI based on the quad-U structure. As can be seen, the four $U$ pieces are mounted in two cores, which are separated by a spacer. The spacer is used to avoid interaction between the fluxes in the two cores. The DC bias winding is wound embracing both cores so that a circulating DC magnetic flux $\phi_{d c}$ is generated inside each core. The AC winding is split into two windings, one on each outer arm of the structure. One of the important points in VI technology is to avoid excessive $\mathrm{AC}$ voltage reflected to the bias winding. As can be seen in Fig. 1 , the quad-U structure successfully meets this requirement by making the AC flux of each AC winding to go through the DC winding in opposite direction. This is achieved by proper connection of the AC windings corresponding terminals, as illustrated in Fig. 1a.

The main advantage of the quad-U structure is that it is completely symmetrical from the point of view of the $\mathrm{AC}$ and DC flux paths, which is not the case of the double-E and tripleE structures. As a consequence, the DC bias flux goes through the entire structure of the quad-U VI and not only through part of it, as it is the case in the double E and triple E structures. This allows the designer to get a further reduction of the inductance for the same VI volume. Consequently, the quad-U structure will provide a larger inductance range for the same size and bias current range.

Even though VIs can be used in DC applications, in this analysis, it will be considered that the main winding produces only an AC magnetic flux, with no DC component. The auxiliary winding handles only a DC current, which generates a DC flux used to bias the core AC magnetic flux. In order to keep the AC flux within limits, an air gap is placed in each core. 
The air gap limits the maximum value of the AC flux, reducing magnetic losses and avoiding possible saturation due to the AC component of the flux. However, a large air gap will have the negative effect of requiring more DC current to achieve the same DC bias flux, which increases the losses in the bias circuit and decreases the efficiency of the structure. Therefore, a thorough analysis of the structure is necessary to achieve an adequate design of the VI.

The DC flux inside the core is used to modulate the permeability of the magnetic material according to its $B-H$ curve from the linear region up to saturation. The change in permeability produces a change of reluctance that finally generates the variation of the $\mathrm{AC}$ inductance of the structure. The main objective of the analysis is to obtain the variation of the $\mathrm{AC}$ inductance as a function of the DC bias current. It is also interesting to determine the DC inductance seen from the auxiliary winding because this inductance is strongly related to the dynamic behavior of the VI, as it was studied in [23].

Fig. 1b illustrates the relevant dimensions of the structure that will be considered in the model. $l_{e}$ and $l_{g}$ are the lengths of the magnetic paths and airgap, respectively. $A_{e}$ is the section of the $\mathrm{U}$ cores. For the airgap, a fringing factor $v_{g}$ will be considered.

\section{Analytical Modeling}

Fig. 2 shows the equivalent reluctance circuit of the quad- $U$ VI. As can be seen, the circuits of both cores are equivalent, being the only difference in the phase of the AC flux in the core, which will not affect the results in terms of amplitudes. Therefore, it is possible to analyze only one of the circuits.

In the circuit of Fig. 2, $\mathfrak{R}_{e}$ and $\mathfrak{R}_{g}$ represent the reluctances of the core and of the airgap, respectively. Their values are given in Table $\mathrm{I}$, where $\mu(B)$ represents the material permeability as a function of the magnetic flux density $(B)$, and $\mu_{0}$ is the permeability of the free space. $\mathcal{F}_{d c}$ and $\mathcal{F}_{a c}$ are the magnetomotive forces (MMF) created by the DC and AC windings respectively, whose values are also provided in Table I. $\phi_{d c}$ and $\phi_{a c}$ represent the magnetic fluxes inside the core.

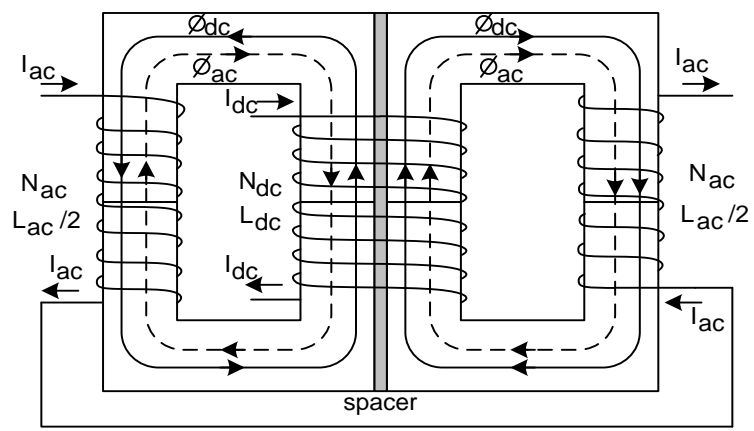

(a)

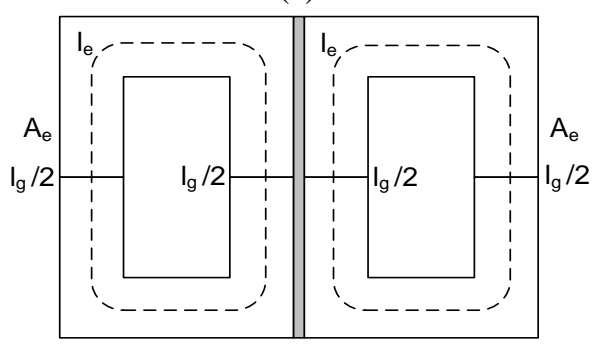

(b)

Fig. 1. (a) VI based on the quad-U structure, (b) Quad-U structure dimensions.
It is assumed that the AC component of the magnetic flux is at least one order of magnitude smaller than its DC level, so that it can be considered as a small signal operation. This is not a very restrictive operating condition because usually the $\mathrm{AC}$ component is made small in order to avoid high magnetic losses in the core material.

Regarding the modeling of the magnetic material, the Brauer's equation that relates magnetic field intensity $(H)$ and magnetic field density $(B)$ will be employed [24], which is shown in Table I. Also, the total permeability $\left(\mu_{t}\right)$ defined as the ratio between $B$ and $H$, and the differential permeability $\left(\mu_{d}\right)$ given by $d B / d H$ are provided in Table I. $k_{1}, k_{2}$ and $k_{3}$ are the parameters of the magnetic material according to the Brauer's model.

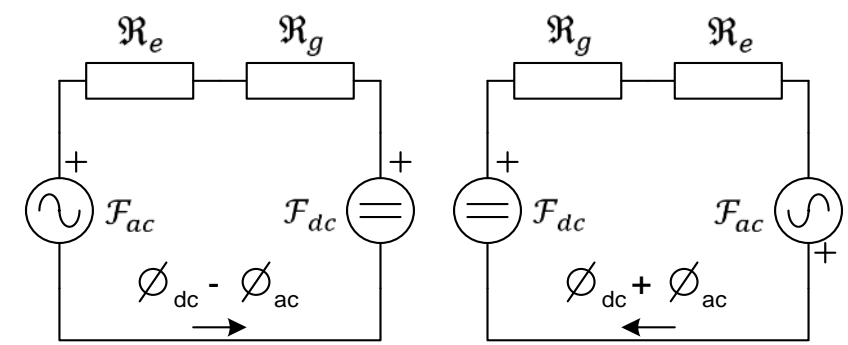

Fig. 2. Equivalent reluctance circuit of the quad-U VI.

Table I. Quad-U VI: Parameters and Quantities of the Reluctance Model

\begin{tabular}{|c|c|}
\hline \multicolumn{2}{|c|}{ Reluctances } \\
\hline$\Re_{e}$ & $\frac{l_{e}}{\mu(B) A_{e}}$ \\
\hline$\Re_{g}$ & $\frac{l_{g}}{\mu_{0} v_{g} A_{e}}$ \\
\hline \multicolumn{2}{|c|}{ MMF } \\
\hline $\mathcal{F}_{a c}$ & $N_{a c} I_{a c}$ \\
\hline $\mathcal{F}_{d c}$ & $N_{d c} I_{d c}$ \\
\hline \multicolumn{2}{|c|}{ Magnetic Material } \\
\hline \multicolumn{2}{|c|}{$H(B)=\left(k_{1} e^{k_{2} B^{2}}+k_{3}\right) B$} \\
\hline & $\mu_{t}(B)=\frac{B}{H}=\left[k_{1} e^{k_{2} B^{2}}+k_{3}\right]^{-1}$ \\
\hline \multicolumn{2}{|c|}{$\mu_{d}(B)=\frac{d B}{d H}=\left[k_{1}\left(1+2 k_{2} B^{2}\right) e^{k_{2} B^{2}}+k_{3}\right]^{-1}$} \\
\hline
\end{tabular}

Since the AC component of the magnetic flux is small compared to the DC level, it is possible to analyze the structure behavior by superposing the DC and AC components of the magnetic flux. Thus, the first step is to calculate the DC operating point. The analysis of the circuit around the DC operating point will provide the information related to the $\mathrm{AC}$ winding inductance, $\mathrm{AC}$ magnetic flux density, magnetic losses, etc.

\subsection{Operating Point}

The equivalent reluctance circuit for DC operation is illustrated in Fig. 3a. In this circuit, it is straightforward to obtain the DC magnetic flux, as follows: 


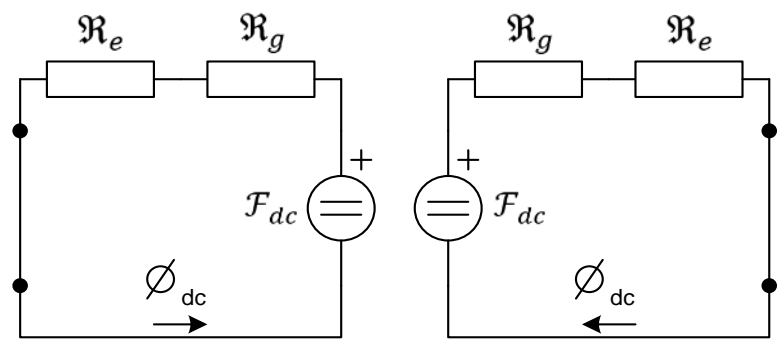

(a)
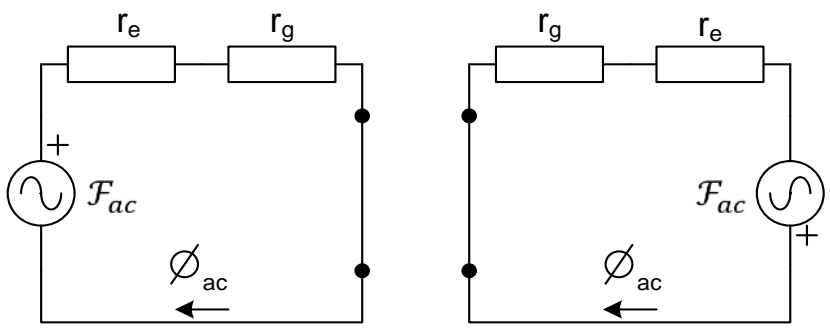

(b)

Fig. 3. (a) DC equivalent reluctance circuit of the quad-U VI, (b) AC equivalent reluctance circuit of the quad-U VI.

$$
\phi_{d c}=\frac{\mathcal{F}_{d c}}{\mathfrak{R}_{e}+\Re_{g}}=\frac{N_{d c} I_{d c}}{\frac{l_{e}}{\mu_{t}\left(B_{d c}\right) A_{e}}+\frac{l_{g}}{\mu_{0} v_{g} A_{e}}}
$$

The DC magnetic flux density can be the calculated by using the following expression:

$$
B_{d c}=\frac{\phi_{d c}}{A_{e}}
$$

Because the reluctances are changing according to the DC magnetic flux density, it is necessary to solve the following equation in order to calculate the DC flux density in the structure:

$$
\phi_{d c}=B_{d c} A_{e}=\frac{N_{d c} I_{d c}}{\frac{l_{e}}{\mu_{t}\left(B_{d c}\right) A_{e}}+\frac{l_{g}}{\mu_{0} v_{g} A_{e}}}
$$

Using the expression of $\mu_{t}$ provided in Table I obtained from the Brauer's model, the final equation to be solved in order to determine $B_{d c}$ is given as follows:

$$
B_{d c}-\frac{N_{d c} I_{d c}}{l_{e}\left(k_{1} e^{k_{2} B_{d c}^{2}}+k_{3}\right)+\frac{l_{g}}{\mu_{0} v_{g}}}=0
$$

Equation (4) can be solved by using a mathematical software. Once the DC component of the magnetic flux density is known, the inductance seen from the DC winding can be calculated. It must be noted that the DC winding carries both DC fluxes, therefore:

$$
L_{d c}=\frac{N_{d c} 2 \emptyset_{d c}}{I_{d c}}=\frac{2 N_{d c} B_{d c}\left(I_{d c}\right) A_{e}}{I_{d c}}
$$

As can be seen from (5), the inductance of the auxiliary winding also depends on the DC operating point. Therefore, as the DC control current is modified to change the main winding inductance, the inductance of the auxiliary windings is also modified, as previously stated in [22]. This is important because this inductance will affect the dynamic response of the VI [23].
It is also important to highlight that, since the DC winding inductance depends on the current through itself, the effective inductance $L_{d c_{-} \text {eff }}$ must be considered when analyzing the dynamic behavior of the bias circuit, which is expressed as follows [25][26]:

$$
\begin{gathered}
v_{L_{-} d c}=L_{d c_{-} e f f} \frac{d i_{d c}}{d t} \\
L_{d c_{-} e f f}=L_{d c}\left(i_{d c}\right)+I_{d c} \frac{d L_{d c}\left(i_{d c}\right)}{d i_{d c}}
\end{gathered}
$$

where $v_{L_{-} d c}$ and $i_{d c}$ represent the instantaneous voltage and current of the DC winding.

\subsection{AC Operation}

The AC component of the flux is superposed to the DC level calculated in previous section. In order to determine the AC flux in the structure, the small-signal equivalent circuit shown in Fig. $3 b$ is considered. In this circuit, the AC reluctances of each arm of the structure are used, whose values are given as follows:

$$
\begin{gathered}
r_{e}=\frac{l_{e}}{\mu_{d}\left(B_{d c}\right) A_{e}} \\
r_{g}=\frac{l_{g}}{\mu_{0} v_{g} A_{e}}
\end{gathered}
$$

By analyzing the circuit in Fig. 3b, the following value of the AC flux is obtained:

$$
\begin{aligned}
\phi_{a c}\left(B_{d c}\right)=\frac{N_{a c} I_{a c}}{r_{e}\left(B_{d c}\right)+r_{g}} & \frac{N_{a c} I_{a c}}{\frac{l_{e}}{\mu_{d}\left(B_{d c}\right) A_{e}}+\frac{l_{g}}{\mu_{0} v_{g} A_{e}}}
\end{aligned}
$$

Then, the AC inductance of each AC winding can be calculated as follows:

$$
\frac{L_{a c}}{2}=\frac{N_{a c} \phi_{a c}}{I_{a c}}
$$

And the total AC inductance of the structure will be given by:

$$
L_{a c}=\frac{2 N_{a c} \phi_{a c}}{I_{a c}}
$$

\section{Example of Quad-U VI Analysis}

In this section, an example of analysis of a VI with a quad U structure is presented. The data of the VI are gathered in Table II.

Equation (4) has been solved for the case of the parameters shown in Table II using WinPython 3.3.5. Thus, the DC component of the magnetic flux density in the $\mathrm{U}$ cores has been obtained. The result is represented in Fig. 4a.

Using (10) the AC flux in the cores can be calculated. From this value the AC flux density can be obtained and represented as a function of the DC bias current. The result is shown in Fig. $4 \mathrm{~b}$ for an AC current of $0.5 \mathrm{~A}$. The maximum value of the AC flux density is $0.132 \mathrm{~T}$ at $0.5 \mathrm{~A}$, which is attained at zero DC bias. This value can be considered small enough as to be consistent with the previous assumption of small signal operation of the AC component. Therefore, the inductance of 
the AC winding is calculated from (12). Fig. 4c illustrates the obtained results.

Finally, using (5) and (7) the inductance and effective inductance of the bias winding are calculated. Fig. $4 \mathrm{~d}$ shows the results as a function of the DC bias current.

\section{Simulation and Experimental Results}

A SPICE-based model of the VI has been developed following the methodology presented in [20]-[23]. The equivalent circuit is illustrated in Fig. 5.

In this model, a non-linear reluctor element has been used for the two magnetic paths of the structure. The definitions of the different elements used in the simulation can be found in [20][23]. A new element has been developed for this work, corresponding to a winding that embraces two independent magnetic paths. The implementation of this element in LTspice is shown in Appendix I. The latest version of the magnetic library developed for this work can be downloaded from the following website https://www.unioviedo.es/ate/marcosaa/.

In the circuit of Fig. 5 the VI is tested similarly as it would be done in the laboratory. The main winding of the VI is supplied with a sinusoidal waveform of $0.1 \mathrm{~V}$ peak. The inductance is obtained through the ratio of RMS voltage and current, which are measured at the VI AC winding terminals. The necessary SPICE directives used to calculate the inductance are also shown in Fig. 5.

Table II. Variable Inductor Data

\begin{tabular}{|l|c|}
\hline \multicolumn{2}{|c|}{ Variable Inductor } \\
\hline AC winding turns, $N_{a c}$ & \multicolumn{1}{|c|}{$25(\varnothing 0.3 \mathrm{~mm})$} \\
\hline DC winding turns, $N_{d c}$ & $130(\varnothing 0.2 \mathrm{~mm})$ \\
\hline DC control current, $I_{d c}$ & $0-0.6 \mathrm{~A}$ \\
\hline AC current range, $I_{a c}$ & $0-0.5 \mathrm{~A}$ \\
\hline Airgap length, $l_{g c}$ & 1.06 \\
\hline Estimated fringing factor, $v_{g}$ & $0.7-0.1 \mathrm{mH}$ \\
\hline Expected inductance range, $L_{a c}$ & $\mathrm{U} 20 / 16 / 7(\mathrm{EPCOS}-\mathrm{TDK})$ \\
\hline \multicolumn{2}{|c|}{$\mathrm{N} 27(\mathrm{EPCOS}-\mathrm{TDK})$} \\
\hline Core length, $l_{e}$ & $68.0 \mathrm{~mm}$ \\
\hline Core area, $A_{e}$ & $55.0 \mathrm{~mm}{ }^{2}$ \\
\hline \multicolumn{2}{|c|}{} \\
\hline Initial permeability, $25^{\circ} \mathrm{C}, \mu_{i}$ & 2000 \\
\hline Flux density at $\mathrm{H}=1200 \mathrm{~A} / \mathrm{m}, 25^{\circ} \mathrm{C}$ & $500 \mathrm{mT}$ \\
\hline Optimum frequency range & $25 \mathrm{kHz}-150 \mathrm{kHz}^{-1}$ \\
\hline \multicolumn{2}{|c|}{$k_{1}=0.1943 \mathrm{Am}^{-1} T^{-1}$} \\
Brauer's model parameters $[20][24]$ & $k_{2}=39.743 \mathrm{~T}^{-2}$ \\
& $k_{3}=127.16 \mathrm{Am}^{-1} T^{-1}$ \\
\hline
\end{tabular}

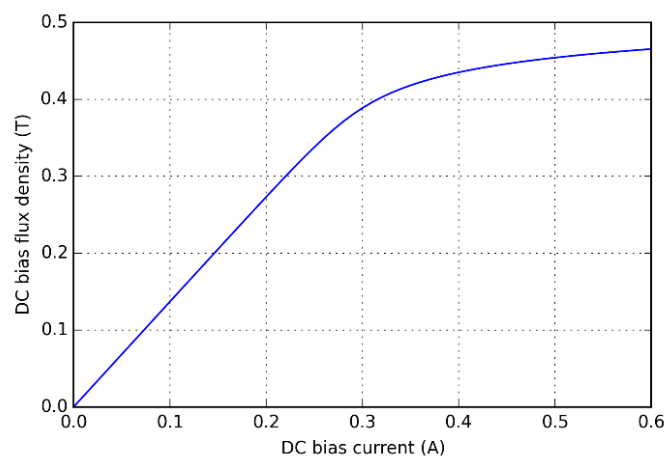

(a)

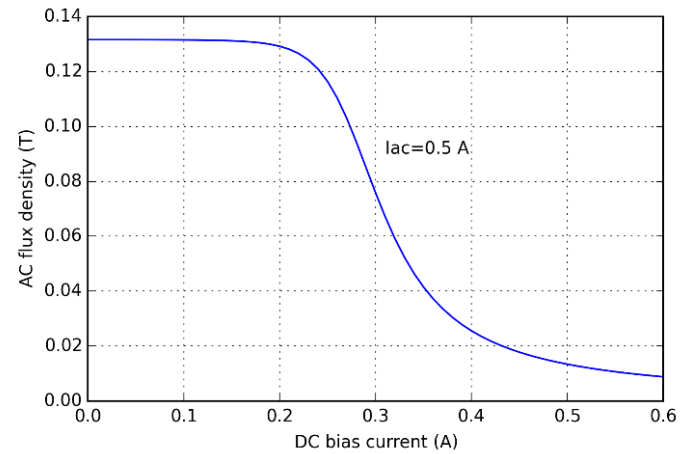

(b)

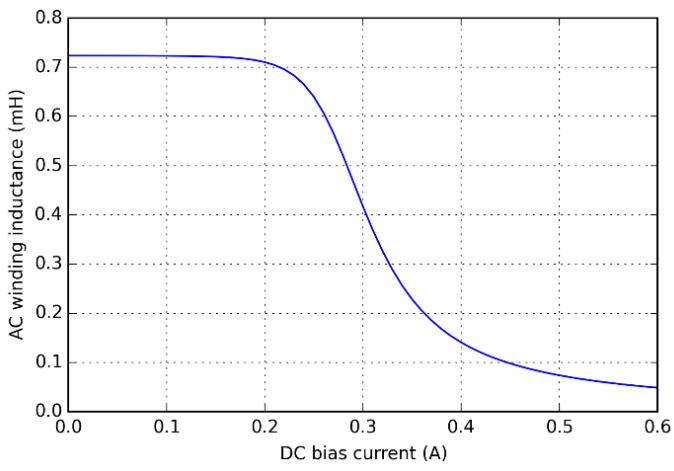

(c)

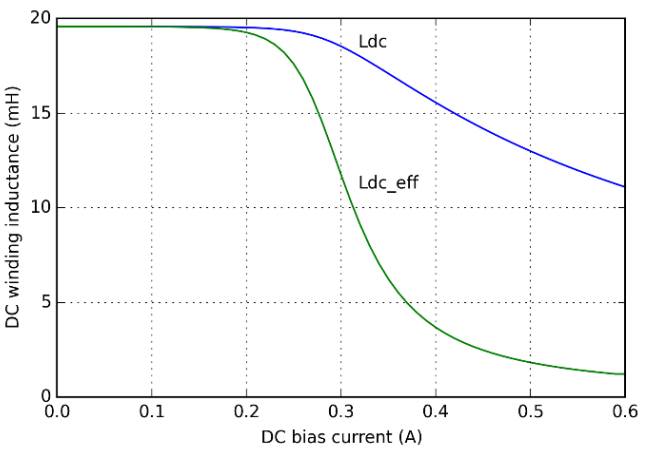

(d)

Fig. 4. (a) DC magnetic flux density in the two cores of the quad-U20 VI under study, (b) AC flux density of the quad-U20 VI versus DC bias current for an AC current of $0.5 \mathrm{~A}$, (c) AC winding inductance of the quad-U20 VI versus DC bias current, (d) DC bias winding inductance $\left(L_{d c}\right)$ and effective inductance $\left(L_{d c_{-} e f f}\right)$ versus DC bias current for the quad-U20 VI under study.

Fig. 6 shows the theoretical results compared with the simulation results obtained from the circuit in Fig. 5. Note that the simulation includes the effect of the flux $\mathrm{AC}$ component inside the core, which has been neglected in the theoretical analysis. As can be observed, the matching between theoretical and simulation results is very good. This proves the validity of the small signal operation assumption made in the theoretical study.

In Fig. 7, the simulation circuit for the determination of the DC bias winding inductance is illustrated. This figure also shows the corresponding SPICE directives to perform the calculations. The DC winding inductance can be obtained directly by the average voltage at net "Ldc" shown in the circuit. The calculation of the effective inductance requires injecting a small AC current superposed to the DC bias current, which is done by the current source I1 by means of the parameters I_ac and I_dc respectively. Then, by dividing the RMS values of the 
small signal current and voltage in the winding, the effective impedance is calculated, and from it the effective inductance is finally obtained. This is done using the .measure statements shown in Fig. 7. Note that, since the effective inductance is lower at higher DC bias currents, it is necessary to increase the value of the AC current injected at the higher values of the DC bias current. Otherwise, the AC voltage across the winding would be too low and would render inaccurate results. The range used in this simulation started from $1 \mathrm{~mA}_{\mathrm{ac}}$ at zero DC bias current up to $20 \mathrm{~mA}_{\mathrm{ac}}$ at $0.55 \mathrm{DC}$ bias current.

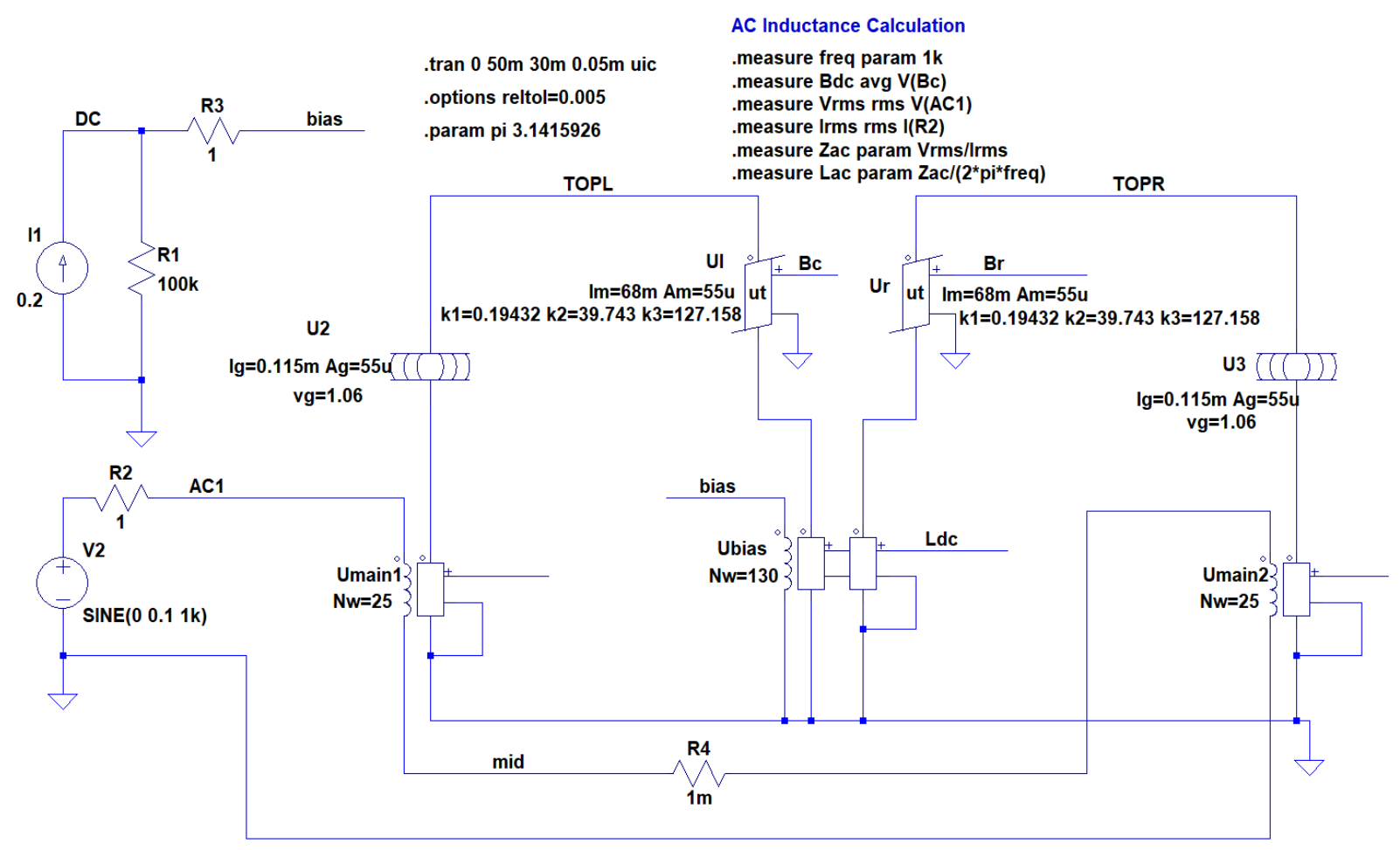

Fig. 5. LTspice circuit for the simulation of the quad-U VI including the calculation of the AC winding inductance.

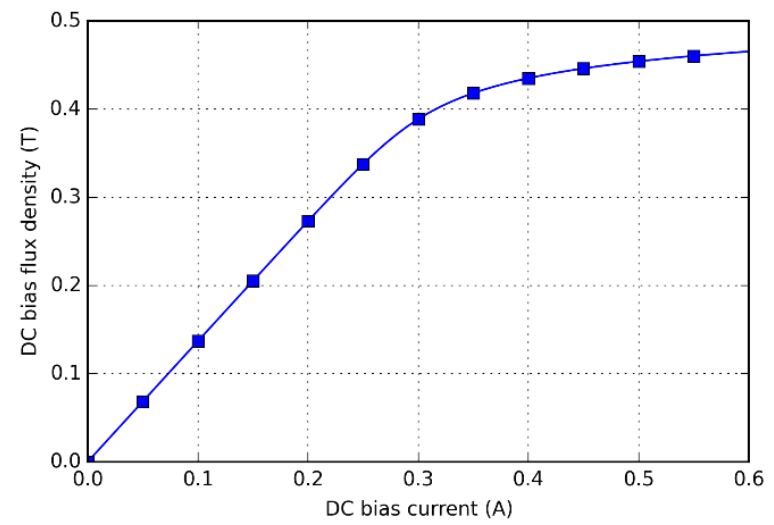

(a)

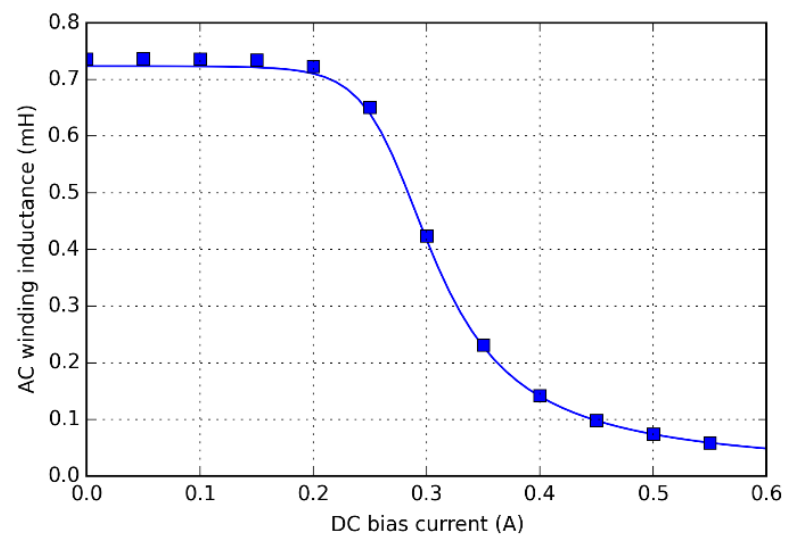

(b)

Fig. 6. (a) DC magnetic flux density in the outer arms: theoretical results (blue solid line) and simulation results (blue squares), (b) AC winding inductance: theoretical results (blue solid line) and simulation results (blue squares). 


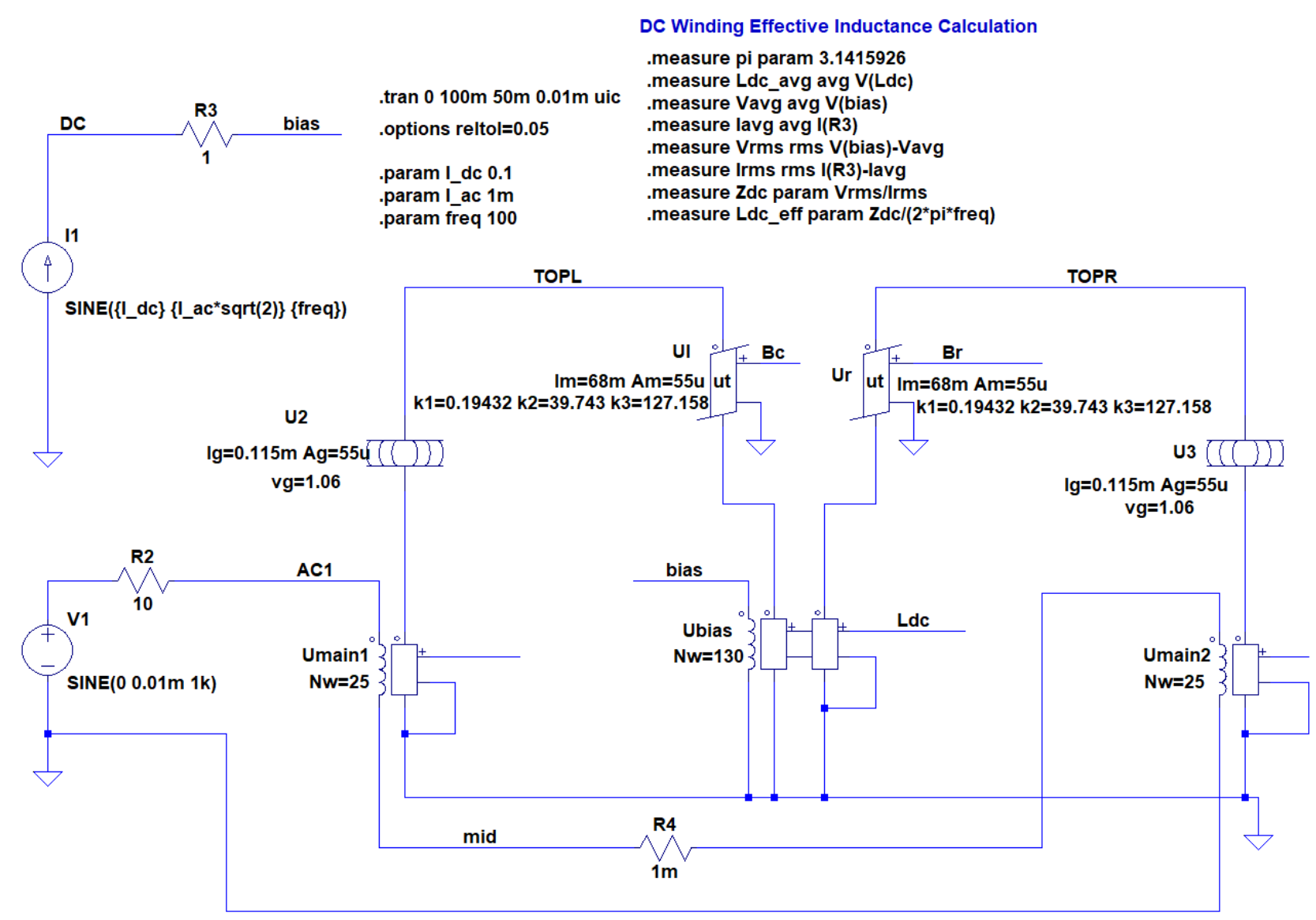

Fig. 7. LTspice circuit for the simulation of the quad-U VI including the calculation of the DC bias winding inductance.

Fig. 8 shows the simulation results obtained from the circuit in Fig. 7 in comparison with the theoretical results. As can be seen, both the inductance and the effective inductance match perfectly the theoretical results obtained from the analytical study.

With regard to the experimental tests, Fig. 9a shows a photograph of the VI laboratory prototype used in the experiments.

The AC inductance of the VI was measured at the laboratory by using an Omicron Bode 100 impedance analyzer. A DC current is injected to the DC bias winding while the $\mathrm{AC}$ inductance is measured using the impedance analyzer. The results are illustrated in Fig. 9b. As can be seen, the correlation is quite good, which proves the usefulness of the developed model.

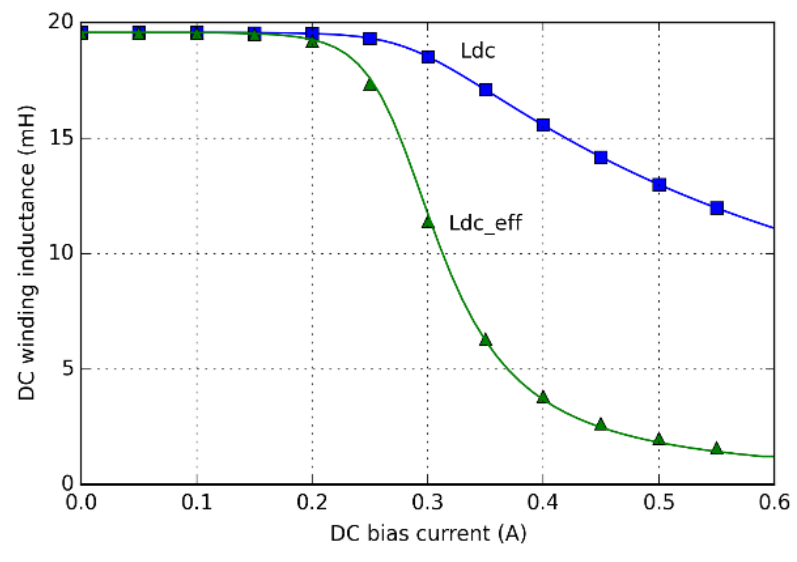

Fig. 8. DC bias winding inductance $\left(L_{d c}\right)$ : theoretical results (blue solid) and simulation results (blue squares). DC bias winding effective inductance $\left(L_{d c_{-} \text {eff } f}\right)$ : theoretical results (green solid) and simulation results (green triangles). 


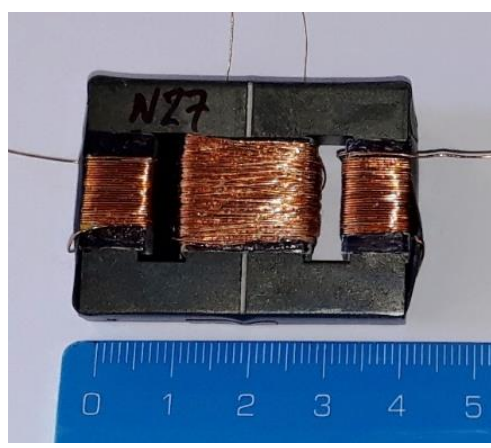

(a)

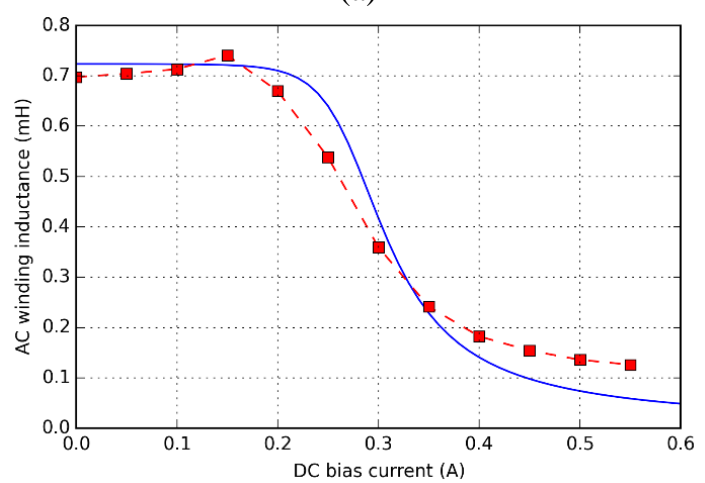

(b)

Fig. 9. (a) Laboratory prototype of the Quad-U VI, (b) AC winding inductance: theoretical results (blue solid line) and experimental measurements (red squares).

Fig. 10a shows the circuit used to measure the effective inductance of the DC bias winding [25][26]. The series choke is used to inject a DC bias current through the winding avoiding any interaction with the impedance analyzer. Also, the impedance analyzer is connected to the winding through a capacitor, which represents a low impedance at the measuring frequency while blocking the DC current from the DC voltage source. The results are shown in Fig. 10b. As can be seen, again a good correlation with the theoretical analysis has been obtained. It must be noted that the matching is much better than that obtained in a previous work [22]. The reason could reside in the fact that the present VI structure presents some airgap in the DC magnetic flux path, which renders more controllable the value of the $\mathrm{AC}$ component of the magnetic flux injected by the analyzer when approaching to the material saturation.

Fig. 11 illustrates the testing of the quad-U VI prototype in a single-inductor LED driver, in a similar application as in [23]. The converter operates at $100 \mathrm{kHz}$ to supply a $15 \mathrm{~W}$ LED lamp; all relevant information is provided in Fig. 11a. Fig. 11b shows the half-bridge output voltage $v_{1}$ and inductor current $i_{1}$ at the minimum (left) and maximum (right) LED power. Fig. 11c shows the LED voltage, current and power as a function of the VI DC bias current. As can be seen, the LED lamp power can be controlled from a minimum of $4 \mathrm{~W}$ to a maximum of $15 \mathrm{~W}$, which demonstrates the feasibility of the proposed solution.

\section{Conclusions}

In this paper the analytical modelling of the quad-U structure of VIs has been presented. The superposition law has been used to obtain the DC and AC components of the magnetic flux of the VI. From this information, the main inductance of the VI has been calculated as a function of the DC control current. The study also provides the DC inductance and effective inductance of the bias winding. Thus, all the important parameters of the VI are obtained.

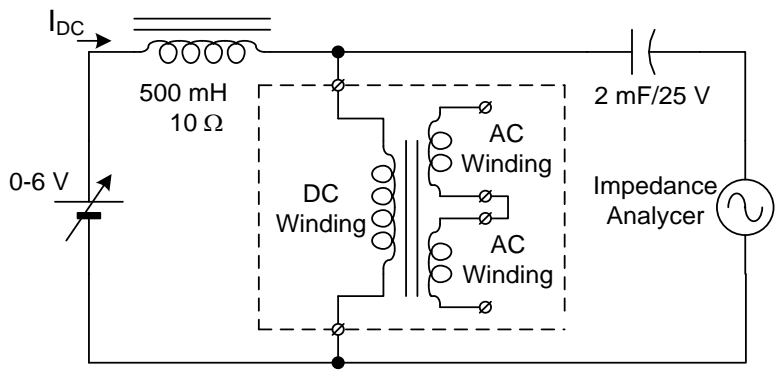

(a)

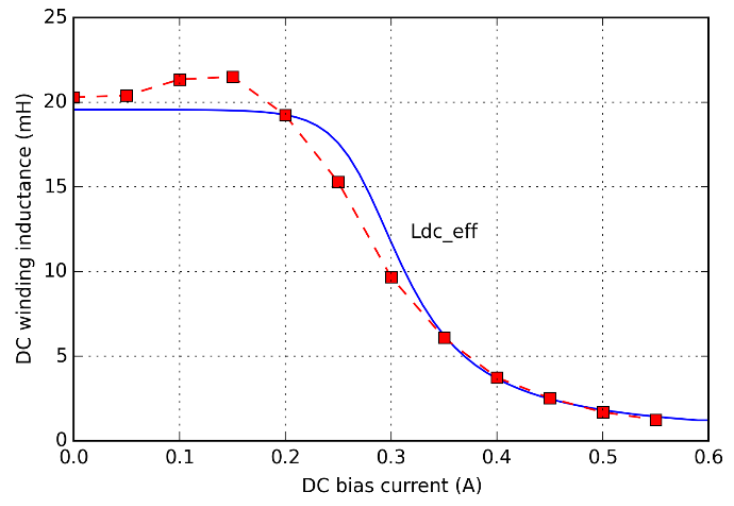

(b)

Fig. 10. (a) Experimental circuit used to measure the effective inductance of the DC bias winding, (b) effective DC winding inductance: theoretical results (blue solid line) and experimental measurements (red squares).

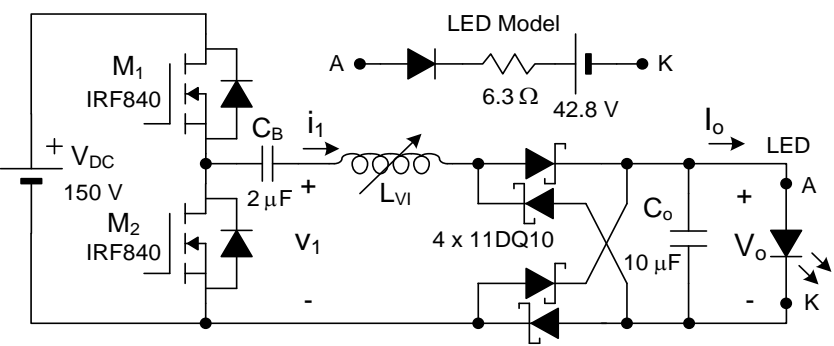

(a)

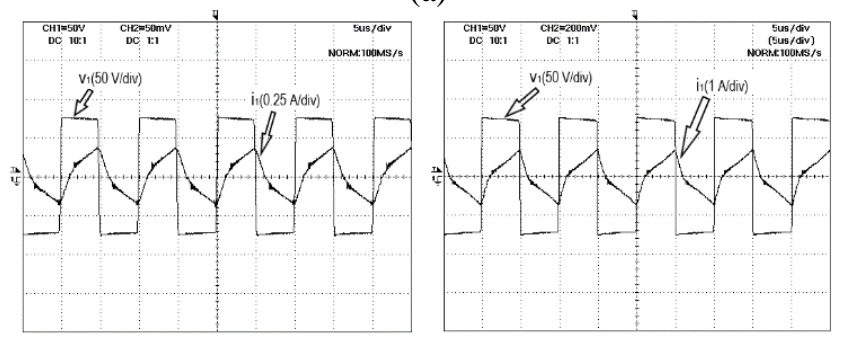

(b) 

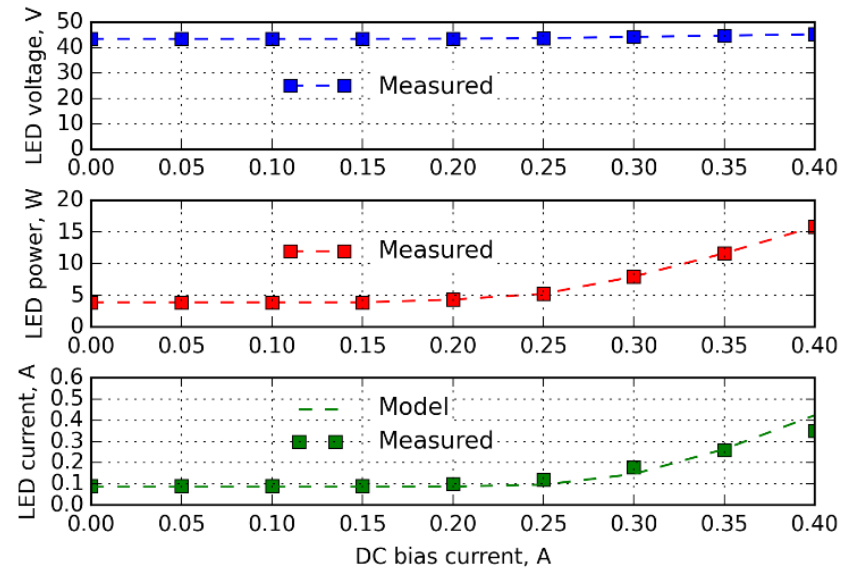

(c)

Fig. 11. (a) VI-based LED Driver, (b) experimental waveforms at minimum (left) and maximum (right) output power, (c) LED lamp voltage, power and current versus VI DC bias current.

A SPICE model for the quad-U VI has also been developed to test the theoretical analysis. Simulation results match perfectly the theoretical analysis, which validates the correct application of the superposition law in the analytical procedure. One of the advantages of the SPICE model developed in this work is that it can be used in simulations including a complete VI-based power converter.

The analyzed VI has also been tested in the laboratory by measuring the main winding inductance and the effective inductance of the DC bias winding. The obtained experimental results matched quite well the results from the theoretical analysis and simulations. Experimental results on a real life single-inductor LED driver prototype have also proven the feasibility of the quad-U magnetic structure.

It has been found that the quad-U structure is completely symmetrical from the point of view of the AC and DC flux paths. This represents an advantage compared with the doubleE and triple-E structures because the DC bias flux goes through the whole magnetic structure of the VI. Therefore, the quad-U structure provides a larger inductance range than the other types of VI for the same size and bias current range.

It must also be stated that the proposed modeling technique based on analytical approach can suffer from several inaccuracies as approximation of the B-H curve, asymmetry of the core and other not considered effects. This is the reason of not having a perfect matching between theoretical and experimental results. Therefore, for a further insight on the VI, a finite element analysis (FEA) would be helpful. However, FEA will usually require much more time for modelling and simulation than the proposed analytical methodology. Only for simulation time, FEA will usually require from minutes to hours depending on the required accuracy, while the calculation time of the analytical approach is in the range of seconds.
Appendix I. LTspice definition of a Winding Implemented around Two Magnetic Arms.

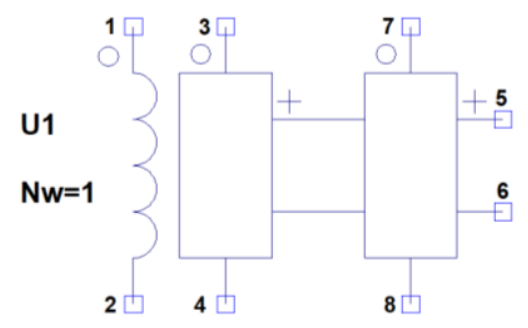

(a)
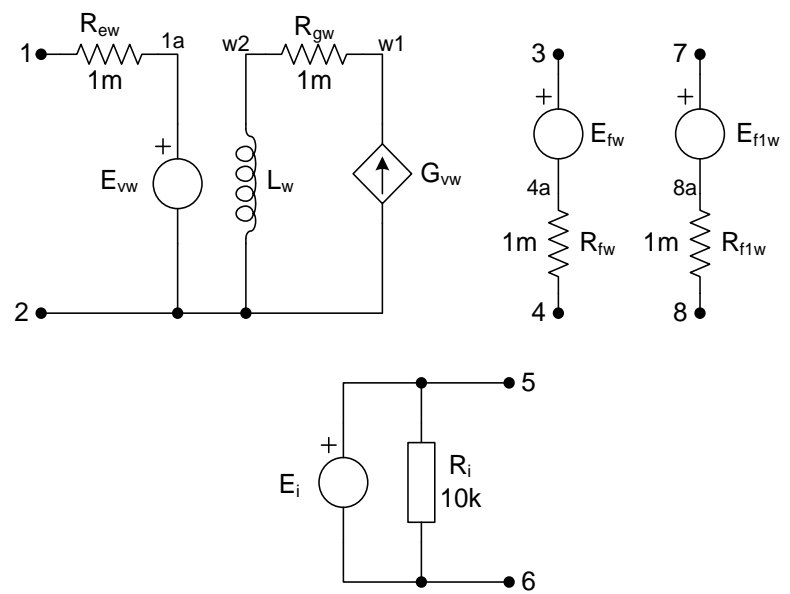

(b)

Fig. AI.1. (a) Symbol, (b) equivalent circuit.

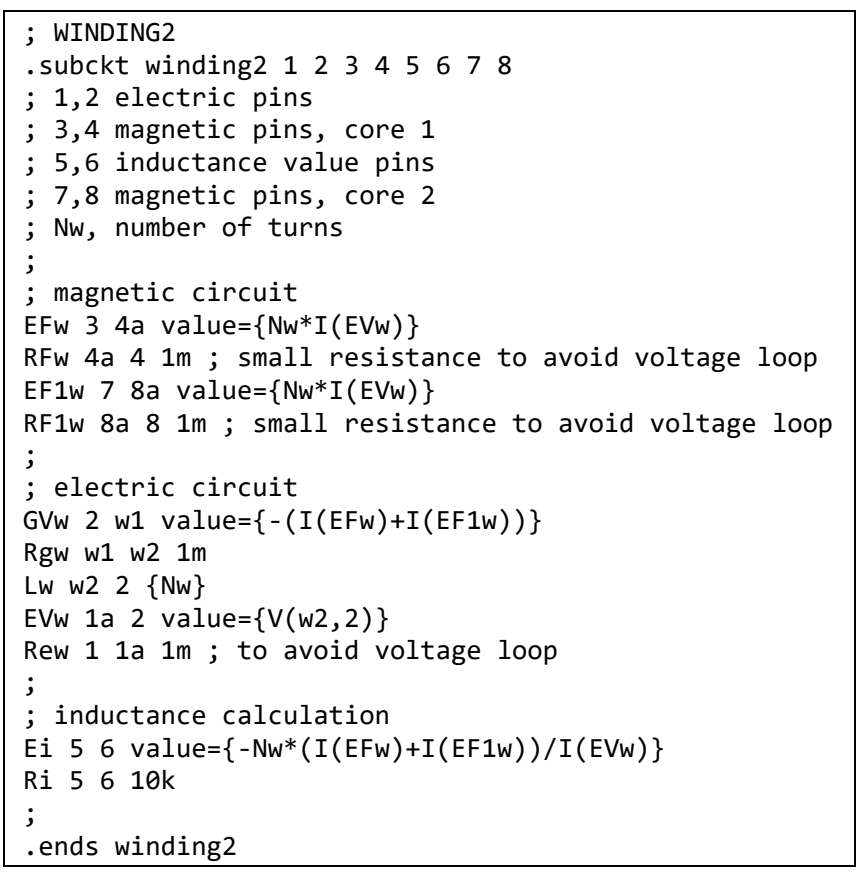

\section{References}

[1] A. S. Kislovski, "Quasi-linear controllable inductor," Proc. of the IEEE, vol. 75, No. 2, Feb. 1987, pp. 267-269.

[2] J. M. Alonso, M. A. Dalla Costa, M. Rico-Secades, J. Cardesín, J. Garcia, "Investigation of a New Control Strategy for Electronic Ballasts Based on Variable Inductor”, IEEE Trans. on Ind. Electr., Vol. 55, No 1, pp. 3-10, Jan. 2008. 
[3] M. F. Menke, M. F. da Silva, A. R. Seidel, M. S. Perdigão and J. M. Alonso, "High power factor dimmable selfoscillating electronic ballast with variable inductor control," IEEE App. Power Electr. Conf. and Expo. (APEC), 2015, Charlotte, NC, 2015, pp. 3314-3321.

[4] M. S. Perdigao, J. M. Alonso, M. A. Dalla Costa, E. S. Saraiva, "Comparative Analysis and Experiments of Resonant Tanks for Magnetically Controlled Electronic Ballasts," Ind. Electr., IEEE Trans. on, vol.55, no.9, pp. 3201-3211, Sept. 2008.

[5] M. S. Perdigao, J. M. Alonso, E. S. Saraiva,

"Magnetically-controlled dimming technique with isolated output," Electr. Letters, vol. 45, no. 14, pp. 756758, July 2009.

[6] M. S. Perdigao, J. M. Alonso, M. A. Dalla Costa, E. S. Saraiva, "Using Magnetic Regulators for the Optimization of Universal Ballasts," IEEE Trans. on Power Electr., vol.23, no.6, pp. 3126-3134, Nov. 2008.

[7] U. Boeke, "Scalable fluorescent lamp driver using magnetic amplifiers," European Power Electr. Conf. and Expo. (EPE), pp. 1-10, 2005.

[8] J. M. Alonso, M. S. Perdigão, D. G. Vaquero, A. J. Calleja, E. S. Saraiva, "Analysis, Design, and Experimentation on Constant-Frequency DC-DC Resonant Converters With Magnetic Control," IEEE Trans. on Power Electr., vol. 27, no. 3, pp. 1369-1382, March 2012.

[9] M. S. Perdigao, J. P. F. Trovao, J.P.F., J. M. Alonso, E. S. Saraiva, "Large-Signal Characterization of Power Inductors in EV Bidirectional DC-DC Converters Focused on Core Size Optimization," Industrial Electronics, IEEE Trans. on, vol.62, no.5, pp. 3042-3051, May 2015.

[10] F. Sichirollo, J. M. Alonso and G. Spiazzi, "Use of current controlled mutual inductor to limit recycling current in the AHB-Flyback converter," IECON 2012 - 38th Annual Conf. on IEEE Ind. Electr. Soc., Montreal, QC, 2012, pp. 4611-4616.

[11] R. A. Pinto, R.A., J. M. Alonso, M. S. Perdigao, M. F. da Silva, R. N. do Prado, "A new technique to equalize branch currents in multiarray LED lamps based on variable inductor," Ind. App. Soc. Annual Meeting, IEEE , pp. 1-9, 5-9 Oct. 2014.

[12] J. M. Alonso, M. Perdigão, M. A. Dalla Costa, G. Martínez, R. Osorio; "Analysis and Design of a Novel Variable-Inductor-Based LED Driver for DC Lighting Grids ," IEEE Ind. Appl. Soc. Ann. Meeting Conf. Rec., Oct. 2016.

[13] C.-Y. Lim, J. H. Kim, Y. Jeong, D.-K Kim, H.-S. Youn, G.-W. Moon, "A high efficiency critical mode boost PFC using a variable inductor," 2016 IEEE 8th Int. Power Electr. and Motion Control Conf. (IPEMC-ECCE Asia), Hefei, 2016, pp. 2792-2797.

[14] Y. Hu, L. Huber and M. M. Jovanović, "Single-Stage, Universal-Input AC/DC LED Driver With CurrentControlled Variable PFC Boost Inductor," in IEEE Transactions on Power Electronics, vol. 27, no. 3, pp. 1579-1588, March 2012.

[15] Q. M. Luo, H. Yan, S. Chen and L. W. Zhou, "Interleaved high step-up zero-voltage-switching boost converter with variable inductor control," in IET Power Electr., vol. 7, no. 12, pp. 3083-3089, 122014.

[16] T. Ge, K. Ngo, J. Moss and M. Lim, "Gap design for nonlinear ferrite cores to maximize inductance," 2014 IEEE Energy Conversion Congress and Exposition (ECCE), Pittsburgh, PA, 2014, pp. 5237-5242.

[17] D. Medini, S. Ben-Yaakov, "A current-controlled variable-inductor for high frequency resonant power circuits," App. Power Electr. Conf. and Exp., pp. 219-225, vol. 1, 13-17 Feb. 1994.

[18] M. S. Perdigao, M. Menke, A. R. Seidel, R. A. Pinto, J. M. Alonso, "A review on variable inductors and variable transformers: Applications to lighting drivers," IEEE Trans. on Ind. App., Jan. 2016.

[19] E. A. Bitencourt, M. R. Cosetin, I. G. Vegner and R. N. do Prado, "A ferromagnetic based variable inductor analysis and design methodology," 2015 IEEE 13th Brazilian Power Electr. Conf. (COBEP/SPEC), Fortaleza, 2015, pp. $1-5$.

[20] J. M. Alonso, G. Martínez, M. Perdigão, M. R. Cosetin and R. N. do Prado, "A Systematic Approach to Modeling Complex Magnetic Devices Using SPICE: Application to Variable Inductors," in IEEE Trans. on Power Electr., vol. 31, no. 11, pp. 7735-7746, Nov. 2016.

[21] J. M. Alonso, M. Perdigao, G. Z. Abdelmessih, M. A. Dalla Costa, Y. Wang, "SPICE Modeling of Variable Inductors and its Application to Single Inductor LED Driver Design," in IEEE Trans. on Ind. Electr., vol. 64, No. 7, 5894-5903, Jul. 2017.

[22] J. M. Alonso, M. Perdigão, M. A. Dalla Costa, S. Zhang, Y. Wang; "Variable inductor modeling revisited: The analytical approach," IEEE Energy Conv. Congress and Expo. (ECCE), pp. 895-902, 2017.

[23] J. M. Alonso, M. Perdigao, M. A. Dalla Costa, G. Martínez and R. Osorio, " Analysis and Experiments on a Single-Inductor Half-Bridge LED Driver with Magnetic Control," IEEE Trans. on Power Electronics, early access, vol. 32, no. 12, pp. 9179-9190, 2017.

[24] J. R. Brauer, "Simple equations for the magnetization and reluctivity curves of steel," Magnetics, IEEE Transactions on, vol.11, no.1, pp. 81, 1975.

[25] W.G. Hurley, W. H. Wölfle; Transformers and Inductors for Power Electronics. Chapter 10. Wiley, 2013.

[26] A. Van den Bossche, V. Valchev; Transformers and Inductors for Power Electronics. Chapter 10. Wiley, 2013. 